\title{
INTRODUCCIÓN A LA BIOMIMESIS
}

Vedoya, Daniel

Instituto de Investigaciones Tecnológicas para el Diseño Ambiental del Hábitat Humano (ITDAHu) Facultad de Arquitectura y Urbanismo - Universidad Nacional del Nordeste (FAU - UNNE) Av. Las Heras $N^{\circ} 727$ - (3500) Resistencia (Provincia del Chaco, República Argentina) Tel. +54 03624420088 / +54 3794529537 - E-mail: devedoya@gmail.com

Cuando observamos una hoja de algún vegetal, se destaca su forma, su color verde, su aroma, hasta podemos, en algunos casos, establecer a qué especie pertenece.

Pasando suavemente los dedos por su superficie reconocemos su textura, suave, en algunas hojas, tersa, en otras, rugosa, áspera, unas son opacas, otras lustrosas, etc.

También apreciamos su espesor, mínimo, separando ambas caras.

Lo que nunca se nos ocurre pensar es qué pasa en su interior, y es esto lo que queremos destacar.

Son sólo tres ingredientes básicos los que participan en el proceso más asombroso que sucede en el interior de una hoja cualquiera: agua, dióxido de carbono y luz solar. Los componentes de los dos primeros son: dos moléculas de Hidrógeno y una de Oxígeno $\left(\mathrm{H}_{2} \mathrm{O}\right)$, en el agua, y una de Carbono por dos de Oxígeno (CO2), en el segundo, comúnmente conocido también como anhídrido carbónico.

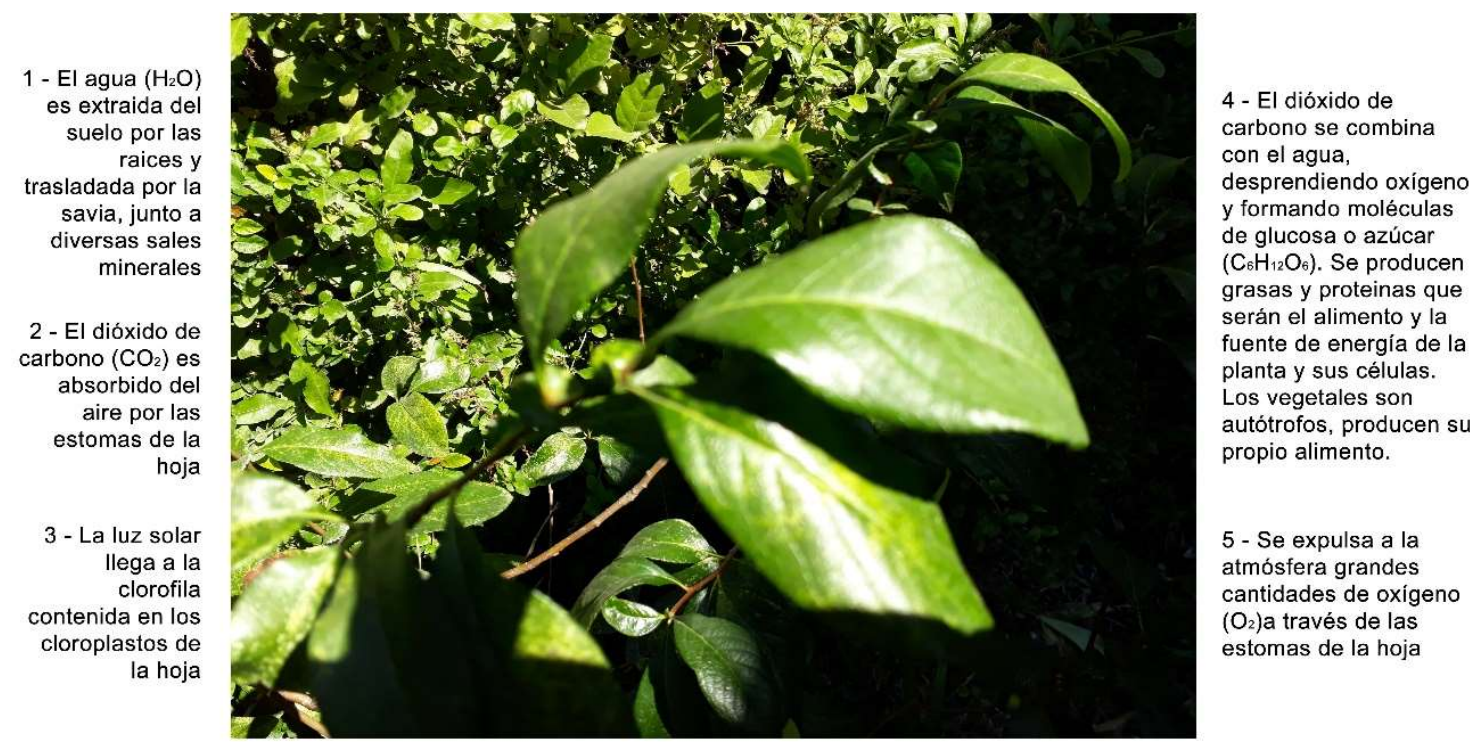

Proceso de fotosíntesis. Fuente: producción propia

El agua es extraída del suelo por las raíces y trasladada por la savia, junto a diversas sales minerales, a toda la estructura orgánica de la planta, hasta la punta de la hoja más distante.

El dióxido de carbono $\left(\mathrm{CO}_{2}\right)$ es absorbido del aire por la hoja a través de las estomas.

La energía solar llega del exterior hasta la clorofila contenida en los cloroplastos de las hojas.

El agua llevada por la savia y el dióxido de carbono se descomponen formando entre sí moléculas de glucosa o azúcar $\left(\mathrm{C}_{6} \mathrm{H}_{12} \mathrm{O}_{6}\right)$, desprendiendo el oxígeno excedente, que vuelve a la atmósfera. De este modo se crean nuevas moléculas (grasas y proteínas) que serán el alimento y la fuente de energía de la planta y sus células. Por esta condición se dice que las plantas son autótrofas, es decir, producen su propio alimento.

Todo este proceso, conocido con el nombre de fotosíntesis, se realiza necesariamente durante el día, mientras se encuentra presente la luz solar. 
En un proceso inverso, durante la noche, la planta respira tomando oxígeno del aire y expulsando dióxido de carbono y agua. Aunque en este proceso las plantas consumen oxígeno, lo hacen en menor cantidad del que producen en la fotosíntesis.

Ese oxígeno que producen durante el día es el que utilizan los seres vivos para respirar.

Lo asombroso de este proceso es que se realiza en un medio natural, sin accesorios especiales, no se necesitan probetas, filtros, etc., como si se tratara de un laboratorio de química.

Vale recordar aquí el pensamiento de Janine Benyus, presidenta y cofundadora del Instituto de Biomimética (Biomimicry Institut) y experta internacional: “...si entramos a un bosque, estamos introduciéndonos en un verdadero laboratorio de química sin necesidad de usar mascarillas ni ningún elemento protector..."

Un bosque maduro es un prodigio de diversidad, donde se optimizan los recursos y se reciclan los residuos. En él conviven arbustos, árboles, enredaderas, musgos, hongos, líquenes, monos, yaguaretés, carpinchos, escarabajos, hormigas, aves diversas, etc. extendiéndose hacia arriba y hacia abajo, llenando cada recoveco de vida, sin producir residuos. Todo desecho de una especie es alimento para otro organismo.

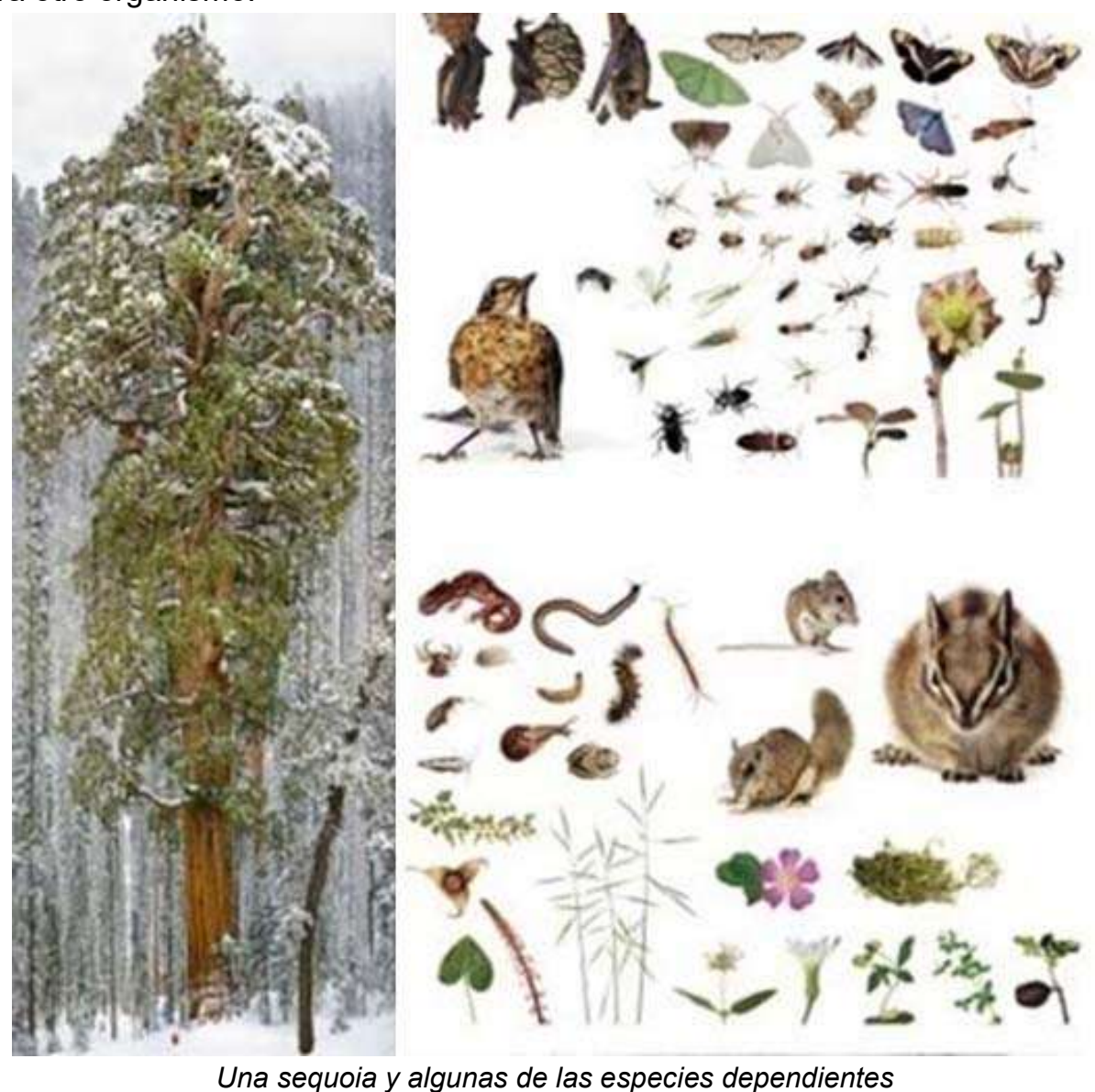

La Naturaleza ha subsistido a través de 4.000 millones de años mediante pruebas de ensayo y error, enfrentando una innumerable cantidad de problemas para los que siempre encontró una solución en forma eficiente, eficaz y de la mejor manera. Lo que ahora vive es lo que funciona. Lo que no ha podido resistir los embates de la evolución ha desaparecido.

A lo largo de su historia ha desarrollado una diversidad de procesos en los que fue renovando, reciclando o reemplazando y, en todos estos casos, no sólo lo ha hecho, sino que lo ha hecho bien.

¿Por qué, entonces, no observar la naturaleza para entender de qué manera ha resuelto sus problemas?

La respuesta a este interrogante la tenemos hoy en la BIOMIMESIS.

Biomimesis surge de la conjunción de dos vocablos: bios = vida y mímesis = imitación (imitación a la vida). No obstante, no se trata sólo de imitar a la naturaleza. 
"La Biomimesis surge en una era basada, no en lo que podemos extraer de la naturaleza, sino de lo que podemos aprender de ella", (Janine Benyus).

Debemos comprender cómo la naturaleza ha resuelto sus problemas para aplicar ese conocimiento a la solución de nuestros propios problemas, observando a la naturaleza para aprender de ella.

Los expertos afirman que el biomimetismo puede ser considerado un campo trascendental para seguir avanzando en mejoras tecnológicas, teniendo en cuenta que el ser humano es tan sólo una de las 1.7 millones de especies que viven en el planeta Tierra.

"No sólo basta conocer las especies, también es importante saber su interrelación, es decir, cómo se ayudan para hacer sus procesos. Toda esta parte es muy interesante para el Biomimetismo y para la humanidad", afirma Melina Ángel, investigadora colombiana del Biomimicry Institute, en Nueva York. Los grandes genios de la humanidad ya hicieron referencia a la necesidad de fijarse en las soluciones propuestas por la naturaleza. De hecho, ésta ha sido la base de inspiración, desde tiempos remotos, de numerosos artistas, arquitectos e ingenieros: Vitruvio, Leonardo da Vinci, Buckminster Füller, Antoní Gaudí, etc.

La biomimesis se presenta así como:

- una rama de la ciencia

- un método para resolver problemas

- un movimiento de un cierto sector de la humanidad

- un paso hacia la naturaleza

- una nueva manera de ver y valorar la biodiversidad

- un punto de partida hacia la sostenibilidad

- una disciplina de diseño

- un aprendizaje de las formas, de los procesos y de los sistemas naturales para crear diseños de tecnologías sostenibles

Las próximas generaciones corren un serio peligro de supervivencia y la biomimesis se presenta como alternativa para enfrentar este problema integrando procesos que tomen ejemplos de la naturaleza, generando empresas ecológicas, que serán mucho más rentables, ofreciendo mejor calidad de vida para los seres humanos

Para esto, necesariamente, debemos antes conocer cómo se comporta la naturaleza, cómo podemos encarar su estudio desde nuestra óptica de arquitectos o ingenieros, qué podemos extraer de este aprendizaje que sea positivo para la solución de nuestros propios problemas.

Es una práctica interdisciplinaria que intenta crear puentes entre el diseño, la arquitectura, la ingeniería, el sector industrial, los negocios y las ciencias de la vida.

Está dirigida a todos los que creen que la innovación y la sostenibilidad son el núcleo de un desarrollo tecnológico completo.

Éste es un momento en que la humanidad debe tomar conciencia del peligro de supervivencia que corren las próximas generaciones.

La biomimesis se presenta aquí ofreciendo una alternativa.

La integración de procesos dentro de sistemas que imitan la naturaleza generan empresas que son ampliamente ecológicas y mucho más rentables, prometiendo una mejor calidad de vida para los seres humanos que trabajan en ella y para sus usuarios.

La vida tiene determinados principios que están identificados en las ciencias biológicas.

La biomimesis ha extraído estos principios para hacerlos aplicables en el mundo humano.

De esta manera, también se crean puentes entre biólogos, arquitectos, ingenieros, tecnólogos y diseñadores en general.

Ante todo esto, debemos cambiar los límites de nuestra comprensión de la naturaleza. Ya no nos alcanzan las unidades de medida con las que estamos acostumbrados a manejarnos en nuestra vida: las medidas que nos permitían comparar distancias, volúmenes, tiempos, ya han dejado de tener vigencia.

Porque nuestro planeta se nos está manifestando de otro modo, por un lado gracias al desarrollo científico y tecnológico que hemos alcanzado en este siglo XXI, y por el otro, porque empezamos a 
descubrir que nuestro planeta y el universo mismo tienen otros límites que debemos tomar de ahora en más.

Al leer y escuchar que los neutrinos pueden viajar a 60 nanosegundos por encima de la velocidad de la luz (casi 300.000 kilómetros por segundo), inmediatamente queremos saber qué es o representa un nanosegundo.

La explicación científica es la siguiente:

- Un segundo: es el tiempo necesario para que un corazón humano, sano, lleve a cabo un latido.

- Una décima de segundo: Es el tiempo en que un colibrí bate las alas un total de siete veces.

- Un milisegundo (10-3; una milésima de segundo): Una mosca bate una vez las alas cada tres milisegundos. La abeja lo hace cada cinco.

- Un microsegundo (10-6; una millonésima de segundo): En este tiempo, un rayo de luz recorre 300 metros.

- Un nanosegundo (10-9; una millardésima de segundo): El microprocesador de un ordenador personal necesita del orden de dos a cuatro nanosegundos para ejecutar una operación (ejemplo: la suma de dos números).

- Un picosegundo (10-12; una billonésima de segundo): A temperatura ambiente, la vida media de un enlace de hidrógeno entre moléculas de agua es de tres picosegundos.

- Un femtosegundo (10-15; una milésima de billonésima de segundo): Un femtosegundo es a un segundo lo que un segundo es a 32 millones de años. El proceso que permite la visión humana (interacción entre la luz y la retina) invierte 200 femtosegundos, aproximadamente.

- Tiempo de Planck (10-43 de segundo): El tiempo más breve imaginable. Según los cálculos actuales, al Big Bang le tomó 2 tiempos de Planck crear todas las fuerzas del universo.

Lo más asombroso de esto no son precisamente estos valores sino el hecho de que se los conoce porque el hombre ha producido los artefactos capaces de medirlos.

Iniciamos nuestro estudio de la naturaleza tomando como base la prédica de Janine Benyus que denominamos "Los diez mandamientos de los ecosistemas":

\section{1 - Convertir los desechos en recursos}

Un sistema ecológico, a medida que acumula biomasa (peso total de materia viva), necesita más reciclaje para evitar el colapso.

Si toda esa biomasa se dedicara sólo a extraer nutrientes del entorno sin reponerlos desde dentro, pronto lo dejaría seco.

En lugar de intercambiar nutrientes y minerales con el entorno, hace circular lo que necesita dentro de su depósito de materia orgánica que nace, muere y se descompone.

Es un conjunto diverso de productores, consumidores y descomponedores que evoluciona, interpretando cada uno su parte, impidiendo la pérdida de recursos.

Todo desecho es alimento.

Lo único que la comunidad importa es cierta cantidad de energía en la forma de luz solar.

Lo único que exporta es un subproducto de su consumo energético: calor.

\section{2 - Diversificarse y cooperar para explotar plenamente el hábitat}

En los ecosistemas maduros, la cooperación es tan importante como la competencia.

Los organismos se distribuyen en nichos no competitivos.

La diversidad de nichos crea una estabilidad dinámica.

Aun cuando los individuos de una misma especie comparten nicho, hay acuerdos sobre la asignación de recursos.

El término simbiosis hace referencia a una relación estrecha que se establece entre dos especies.

Si ambas obtienen un beneficio hablamos de mutualismo. 
Si una obtiene un beneficio pero la otra se queda igual hablamos de comensalismo.

Si una especie obtiene un beneficio a costa de perjudicar a la otra hablamos de parasitismo.

Muchas de las relaciones son tan estrechas que las dos especies se necesitan para poder vivir.

El pequeño camarón extrae parásitos de los afilados dientes de la morena, y a cambio la morena renuncia a comerse al camarón y lo protege de otros predadores.

Los líquenes representan un convenio entre dos especies: un alga y un hongo. Cuando se juntan, el alga capta la energía solar, el hongo proporciona un soporte seguro.

\section{3 - Obtener y usar eficientemente la energía}

En las comunidades naturales los agentes que adquieren la energía son los fotosintetizadores: plantas verdes, algas verdeazuladas y ciertas bacterias.

Al ser una de muchas especies compitiendo por una parte de la energía del sol no pueden permitirse un uso caprichoso de esa energía.

Los animales recorren distancias mínimas para obtener lo que necesitan, y programan sus actividades para maximizar sus recompensas y minimizar el consumo energético.

Animales y plantas protegen tenazmente lo que se aseguran.

Al visitar un bosque descubrimos el ingenioso colector solar de la naturaleza.

Las hojas se distribuyen a fin de maximizar la exposición, y algunas se inclinan y giran a medida que el sol atraviesa el cielo.

Este proceso de eficiencia proporciona energía a todos los seres vivos.

\section{4 - Optimizar en vez de maximizar}

Un campo de plantas anuales prioriza la producción, convierte nutrientes en biomasa, renueva la biomasa y devuelve las plantas al sistema cuando mueren.

Al año siguiente, las plantas vuelven a comenzar de cero, acumulando los nutrientes necesarios para su rápido crecimiento.

Un sistema maduro, al contrario, conserva sus materiales y nutrientes, y en lugar de extraer nutrientes para luego dejarlos escapar cada año, la mayor parte de la biomasa permanece.

En el modo maduro, la selección natural premia a los organismos eficientes que aprenden a hacer más con menos.

Los que sobreviven son los que viven dentro de sus posibilidades.

\section{5 - Consumir materiales con moderación}

Los organismos construyen para durar, pero no construyen más de la cuenta.

Ajustan la forma a la función, construyendo justo lo necesario con el mínimo de materiales y esfuerzo. Los panales de las abejas es un ejemplo de estructura que abarca un espacio máximo con un mínimo de material.

Las abejas esculpen cada celdilla hexagonal con paredes que representan sólo el $2 \%$ del volumen total del panal, logrando una estructura resistente sin malgastar cera.

El hueso tiene una forma ajustada a la función. Es un material liviano que tiene un diseño que resiste la tracción y la compresión.

Los organismos también han evolucionado para sacar el máximo provecho de cada diseño, haciendo que una estructura cumpla no una, sino dos o tres funciones.

\section{6 - No ensuciar el propio nido}

Los organismos comen, respiran y duermen en sus propias plantas de producción, su hábitat, por lo que no pueden permitirse envenenarse con sus residuos.

Tampoco recurren a temperaturas altas, sustancias corrosivas o presiones elevadas en sus procesos de producción, como hacen los humanos.

Saben que un flujo excesivo o una energía fuera de sitio pueden estropear el nido.

La moderación en el consumo energético y material es una norma. 
Gracias a que no fuerzan las líneas de suministro ni los mecanismos de limpieza de su entrono, los organismos se ganan el derecho a seguir viviendo donde viven.

La vida de los organismos no se limita a mantener el nido limpio, sino a crear las condiciones necesarias para la vida.

El ser humano es el único que olvidó esto, e insiste en contaminar los pulmones y filtros del mundo, demostrando una profunda indisciplina.

\section{7 - No agotar los recursos}

En un ecosistema maduro los organismos viven de los intereses y no de un capital principal.

El mejor predador es el que no extermina su presa.

El parásito prudente es el que no mata a su huésped.

Los voraces gorilas se trasladan lentamente por la jungla permitiendo que las plantas de que se alimentan vuelvan a crecer tras ellos.

Todos han aprendido de sus genes que arrancar de raíz se reserva de alimentos no es buena idea.

Dos corolarios del precepto "no emitir contaminantes más deprisa de lo que la tierra puede asimilarlos", deberían ser:

1. No consumir recursos no renovables más deprisa que el desarrollo de sustitutos.

2. No consumir recursos renovables más deprisa de lo que pueden reponerse.

\section{8 - Mantenerse en equilibrio con la biosfera}

La biosfera (capa de aire, tierra y agua que sustenta la vida) es un sistema cerrado, lo que significa que no importa materiales.

Las reservas de los principales elementos de construcción bioquímica (carbono, nitrógeno, azufre y fósforo) se mantienen constantes. No obstante, los organismos los intercambian constantemente.

Todo lo que se extrae de los reservorios de recursos a través de procesos de fotosíntesis, respiración, crecimiento, mineralización y descomposición se repone en la misma medida, como si pasaran por una puerta giratoria de los organismos, donde las reservas circulan sin gastarse.

Los gases atmosféricos también se encuentran en un equilibrio dinámico.

En la fotosíntesis, las plantas inhalan dióxido de carbono y exhalan oxígeno.

Los animales que respiran inhalan este oxígeno y exhalan dióxido de carbono.

A través de este intercambio, la vida mantiene las condiciones que le son necesarias.

Las plantas son la base de la cadena alimentaria en los ecosistemas terrestres.

Son las primeras en la cadena y una pieza fundamental en ésta.

La materia muerta de las plantas y las raíces ayudan a generar la gran parte de la materia orgánica en el suelo de los ecosistemas terrestres.

Las plantas son capaces de alterar el clima ya que humedecen el ambiente y detienen los vientos.

En los bosques se suelen formar microclimas.

Ayudan a la biodiversidad ya que tienen una gran variedad de especies, crean nuevos hábitats y brindan alimento para otros organismos que hace que éstos sean favorables a la biodiversidad.

Las plantas actúan como filtro del agua de los suelos, interviniendo en el ciclo del agua depurando cauces o extrayendo agua subterránea.

\section{9 - Regirse por la información}

Las comunidades maduras son ricas en canales de comunicación que establecen vínculos retroactivos entre todos sus miembros orientados hacia la sostenibilidad.

Cualquier organismo rodeado por, y dependiente de determinados vínculos debe adquirir modos de indicar sus intenciones e interaccionar con sus vecinos.

Un rico sistema retroactivo permite que cualquier cambio en un comportamiento reverbere a través de la comunidad entera, permitiendo la adaptación cuando cambia el entorno.

Es lo que empiezan a destacar los procuradores de la sostenibilidad para nuestras comunidades.

Los lobos perfeccionan sus gestos rituales para comunicar claramente situaciones tales como "aparéemonos" o "ganaste, me retiro en paz". 
De acuerdo con los biólogos, los diseños corporales y comportamientos exitosos deben tener un contenido informativo elevado.

\section{0 - Comprar localmente}

Los animales no pueden importar productos. Compran localmente y se vuelven expertos en sus propios barrios.

Los pumas, por ejemplo, coevolucionan con las cabras montañesas desarrollando una imagen de búsqueda de su presa y el perfecto complemento de física y dientes necesarios para atraparlas y digerirlas.

Las cabras, por su parte, son igualmente adeptas a su terruño, donde han encontrado diversas maneras inteligentes para defenderse de un enemigo conocido.

Quedarse cerca en casa es un acierto porque permite conservar la energía y hacer el mejor uso de las aptitudes de un organismo.

Con la excepción de algunas especies migratorias que vuelan muy alto, la naturaleza no viaja para ir al trabajo.

Finalmente, encaramos el estudio de la naturaleza con tres enfoques diferentes:

- desde las FORMAS

- desde los PROCESOS

- desde los SISTEMAS

La aplicación del conocimiento de la naturaleza a problemas de diseño podrá ser encarado a través de tres caminos diferentes:

1. El análisis de un caso real de biomimética

2. La aplicación de una solución natural al diseño de un objeto tecnológico

3. La resolución de un problema técnico aplicando principios de biomimética

Como corolario, nuestra reflexión antes de iniciar cualquier proceso de diseño.

Lo que iremos a diseñar:

¿Depende de la luz solar?

¿Gasta sólo la energía que necesita?

¿Se ajusta su forma a su función?

¿El objeto es reducible, renovable o recicable?

¿Prima la cooperación?

¿Cuenta con la diversidad?

¿Utiliza la pericia local?

¿Es bello? 